\title{
Characteristics of footwear worn by people with systemic lupus erythematosus: a comparison with age- and sex-matched healthy controls: a pilot study
}

\author{
Sarah Stewart ${ }^{1 *}$, Monique Keys ${ }^{1}$, Angela Brenton-Rule ${ }^{1}$, Ashok Aiyer ${ }^{1}$, Nicola Dalbeth ${ }^{2,3}$ and Keith Rome ${ }^{1}$
}

\begin{abstract}
Background: To determine characteristics of footwear worn by people with systematic lupus erythematosus (SLE). Methods: Twenty-two people with SLE and twenty matched healthy controls participated in a cross-sectional study. Objective assessments of footwear included: fit, style, structure, motion control, cushioning, and wear. Footwear was classified as poor, average or good based on a standardised tool. Participants completed 100mm visual analogue scales for foot pain and footwear comfort and suitability. Participants with SLE were asked to indicate which footwear features were important to them using a validated checklist.

Results: No differences were observed between groups for footwear fit, age, style, heel height, forefoot flexion or cushioning (all $P>0.05$ ). Compared to controls, a greater number of participants with SLE wore shoes with worn tread (65\% vs. $91 \%, P=0.041)$, wore shoes with a lower motion control scale (median: 5.0 vs. 1.0, $P=0.003$ ), and rated their footwear as less comfortable (median: $90 \mathrm{~mm}$ vs. $78 \mathrm{~mm}, P=0.024$ ) and less suitable (median: $88 \mathrm{~mm}$ vs. $76 \mathrm{~mm}$, $P=0.030$ ). Participants with SLE experienced greater foot pain than controls (median: $17 \mathrm{~mm}$ vs. $0 \mathrm{~mm}, P=0.038$ ). Comfort (95\%), fit (95\%) and style (86\%) were identified as the most important footwear features by people with SLE.

Conclusions: Compared to control participants, people with SLE wear shoes that are more worn and lack motion control. They also report greater foot pain and report their shoes to be less comfortable and suitable. These findings highlight the need for a further focus on the role of footwear in the management of foot problems in people with SLE.
\end{abstract}

Keywords: Systematic lupus erythematosus, Footwear, Foot pain

\section{Background}

SLE is a multisystem autoimmune disease that manifests in many systems, including vascular, neurological, musculoskeletal and cutaneous tissues [1-3]. SLE frequently affects peripheral structures, with the foot and ankle region being common areas of involvement [4]. Foot problems in people with SLE include impaired peripheral blood flow $[5,6]$, peripheral neuropathy [7], toe

\footnotetext{
* Correspondence: sarah.stewart@aut.ac.nz

${ }^{1}$ Department of Podiatry, Health \& Rehabilitation Research Institute, Auckland University of Technology, Private Bag 92006, Auckland 1142, New Zealand Full list of author information is available at the end of the article
}

deformities $[8,9]$, joint swelling $[10,11]$, skin and nail changes $[8,10,12]$ and gait changes $[10,11,13]$.

Footwear is important in providing protection, accommodating deformity and assisting function [14]. Different footwear characteristics, including heel height, lack of support and poor fit, may result in increased pain as well as the development of musculoskeletal complications such as osteoarthritis and hallux valgus in otherwise healthy people, as well as foot pain and impairment in people with inflammatory arthritis, including gout [15] and rheumatoid arthritis[16]. Footwear difficulties have also been linked to psychosocial factors, including the aesthetic appearance of footwear which had been

(C) The Author(s). 2018 Open Access This article is distributed under the terms of the Creative Commons Attribution 4.0 International License (http://creativecommons.org/licenses/by/4.0/), which permits unrestricted use, distribution, and 
identified as a major limiting factors in footwear selection in women with rheumatic disease [17]. In fact, female patients with rheumatoid arthritis choose not to wear specialist therapeutic footwear due to the associated restrictions in clothing and contribution to social isolation [18]. In a recent survey, $52 \%$ of people with SLE reported difficulty wearing different shoes [11]. A subjective global podiatric assessment of footwear found that $48 \%$ of people with SLE wore shoes deemed as 'inappropriate', compared with $35 \%$ of control participants [8].

Despite the frequency of foot complications in people with SLE, and the association between footwear characteristics and foot problems in other inflammatory conditions, a detailed objective assessment of footwear has not yet been undertaken in people with SLE. The aim of this study was to describe, in detail, the characteristics of footwear worn by people with SLE.

\section{Methods}

\section{Participants}

This cross-sectional observational study involved a total of 42 participants, including 22 people with SLE and 20 age- and sex-matched healthy controls. Participants were recruited via convenience sampling and this sample size was determined by a fixed 10 week recruitment and data collection period (December 2017 to February 2018). Auckland University of Technology (AUT) Ethics Committee approved the study (AUTEC 16/209). All participants with SLE were diagnosed by a rheumatologist, and fulfilled the SLICC criteria for the classification of SLE [19]. Participants with SLE were recruited from secondary care rheumatology clinics in the Auckland region, New Zealand. Control participants were recruited from AUT staff through poster and newsletter advertising. Participants in both groups were included if they were $\geq$ 20 years of age, were able to read English, and had no recent foot surgery or trauma, neuromuscular conditions or other rheumatic diseases. All participants provided written informed consent prior to the collection of data.

\section{Data collection}

All participants attended a single clinical visit between the months of December 2017 to February 2018 (New Zealand summer). Participants were asked to wear the footwear they had worn most often over the previous month to the study visit. Demographic information and clinical history were obtained from participants during the study visit.

A footwear assessment tool was used to objectively examine the detailed footwear characteristics of the shoes worn by the participants during the study visit [14]. The footwear assessment tool is comprised of six components that cover fit, general features, general structure, motion control properties, cushioning and wear patterns. All components in this tool demonstrate high intra- and inter-rater reliability [14]. Each item from the motion control category was scored from a range of 0 to 11, in which footwear with a score of 11 was considered to possess optimal motion control properties.

In addition, footwear was classified as being poor, average or good using a footwear classification tool [20]. Poor footwear were classified as those which lacked support and sound structure, including sandals, flip-flops (jandals), slippers, mules and moccasins. Average footwear was comprised of hard or rubber-soled shoes and work boots and good footwear was classified as athletic shoes, walking shoes, therapeutic footwear or Oxford type shoes [20].

Participants were also asked to identify feature(s) of footwear that they considered important when they choose and wear shoes, using a validated checklist [21]. This checklist has been used to assess footwear features in other inflammatory arthropathies [22, 23] and includes items such as comfort, style, fit, support, cost, weight and colour. Self-perceived comfort and suitability of current footwear were assessed using $100 \mathrm{~mm}$ visual analogue scales (VAS). In addition, foot pain for the foot with the greatest pain at the time of the study visit was assessed using $100 \mathrm{~mm}$ VAS.

\section{Statistical analysis}

All demographic and clinical data were described as mean (SD) for continuous data and $\mathrm{n}$ (\%) for categorical data. To determine whether there were differences in footwear characteristics between groups, Wilcoxon signed rank tests (for non-parametric continuous data or ordinal data) and McNemar's chi-square tests (for binary data) were used. All analyses was undertaken in SPSS v. 24.

\section{Results}

Participant demographic and clinical data are summarised in Table 1. Participants were predominantly middle-aged females. Participants with SLE had a mean (SD) disease duration of 14 (10) years. Participants with SLE and controls were generally well matched for age, sex, ethnicity and body mass index.

Table 2 summarises the footwear characteristics. There was no significant difference between footwear worn by people with SLE and controls in terms of fit, style, classification, longitudinal profile, forefoot flexion point and cushioning. A greater number of people with SLE wore shoes that had partly or fully worn tread, compared to controls ( $91 \%$ vs. $65 \%, P=0.041)$. The most common footwear style worn by both groups was walking shoes ( $n=7$ (32\%) SLE, $n=7$ (35\%) controls), followed by open-toed shoes, including sandals $(n=6,(27 \%)$ SLE, $n=5$ $(25 \%)$ controls) and flip flops $(n=3$ (14\%) SLE, $n=1$ (5\%) 
Table 1 Participant demographic and clinical characteristics

\begin{tabular}{|c|c|c|}
\hline & SLE & Control \\
\hline $\mathrm{N}$ & 22 & 20 \\
\hline Sex, female, n (\%) & 20 (91\%) & $18(90 \%)$ \\
\hline Age, years & $51(15)$ & $51(12)$ \\
\hline \multicolumn{3}{|l|}{ Ethnicity, n (\%) } \\
\hline European & $13(59 \%)$ & $17(85 \%)$ \\
\hline Māori & $2(9 \%)$ & $1(5 \%)$ \\
\hline Pacific & $1(5 \%)$ & $0(0 \%)$ \\
\hline Asian & $6(27 \%)$ & $1(5 \%)$ \\
\hline Other & $0(0 \%)$ & $1(5)$ \\
\hline Body mass index, $\mathrm{kg} / \mathrm{m}^{2}$ & $27.1(7.0)$ & $26.3(5.3)$ \\
\hline SLE disease duration, years & $14.3(10.3)$ & - \\
\hline SLEDAI-2K & $12.0(8.2)$ & - \\
\hline \multicolumn{3}{|l|}{ Medications, n (\%) } \\
\hline Hydroxychloroquine & $12(55 \%)$ & \\
\hline Immunosuppressive & $10(42 \%)$ & \\
\hline NSAID & $10(45 \%)$ & \\
\hline Prednisone & $11(50 \%)$ & \\
\hline \multicolumn{3}{|c|}{ Comorbidities and complications of disease, $\mathrm{n}(\%)$} \\
\hline Raynaud's syndrome & $9(41 \%)$ & \\
\hline Lupus nephritis & $3(14 \%)$ & \\
\hline Hypertension & $3(14 \%)$ & \\
\hline Cardiovascular disease & $2(9 \%)$ & \\
\hline Dyslipidaemia & $2(9 \%)$ & \\
\hline Sjögren syndrome & $2(9 \%)$ & \\
\hline Osteoporosis & $2(9 \%)$ & \\
\hline Fibromyalgia & $1(5 \%)$ & \\
\hline Depression & $2(9 \%)$ & \\
\hline
\end{tabular}

Values are presented as mean (SD) unless otherwise indicated. SLEDAI-2K: systematic lupus erythematosus disease activity index - 2000; NSAID: nonsteroidal anti-inflammatory drug

controls). The majority of participants with SLE wore shoes classed as poor $(n=14,64 \%)$ however, this was not significantly different from controls $(n=9$ (45\%), $P=$ 0.47 ). The majority of shoes worn in both groups had no heel height and around one-third of participants wore shoes with forefoot flexion points distal or proximal to the metatarsal heads. Participants with SLE wore shoes with a lower motion control properties scale compared to controls (median: 1.0 vs. 5.0, $P=0.003$ ).

Participants with SLE rated their footwear as less comfortable (median: $78 \mathrm{~mm}$ vs. $90 \mathrm{~mm}, P=0.024$ ) and suitable (median: $76 \mathrm{~mm}$ vs. $88 \mathrm{~mm}, P=0.030$ ) compared to controls. Participants with SLE had greater foot pain compared to controls (median: $0 \mathrm{~mm}$ vs. $17 \mathrm{~mm}, P=0.038$ ). Table 3 shows the differences in features of footwear perceived as important or very important between people with SLE and controls. The most commonly identified factors for both groups were comfort (95\% SLE vs 100\% controls), fit (95\% SLE vs $100 \%$ controls) and style (86\% SLE vs $90 \%$ controls). Only ease to put on and take off the shoe was significantly different between groups (82\% SLE vs $50 \%$ controls, $P=0.029$ ).

\section{Discussion}

This is the first study to undertake a comprehensive assessment of footwear worn by people with SLE. The findings show that overall, footwear characteristics are similar between people with SLE and age- and sex-matched controls in terms of fit, age, style, heel height, forefoot flexion and cushioning. However, people with SLE wore shoes that were more worn, lacked motion control properties and were reported to be less suitable and less comfortable compared to those worn by healthy volunteer controls.

People with SLE wore shoes with less motion control properties compared to controls. These properties include stiffness of the heel counter, which is important in controlling rearfoot motion, and sagittal and frontal plane stability which are importing in controlling motion through the midfoot [14]. Although the sample size was not powered to determine the relationship between foot characteristics and foot problems, prior studies have shown that adequate motion control is important in managing foot problems in people with rheumatoid arthritis and gout $[15,16]$ and is associated with lower foot-related pain and disability in people with gout [23].

Although the majority of participants with SLE wore shoes classed as poor, including sandals and flip flops, their shoe choice did not differ from the control participants. The frequent use of poor footwear by people with SLE observed in the current study is similar to a previous study of foot problems in people with SLE, which described a subjective assessment of footwear appropriateness [8]. It should be noted that the current study was conducted over summer, and previous research has shown seasonal variation in footwear worn by people with inflammatory arthritis, who frequently wear sandals in summer to prevent their feet over-heating [24].

Consistent with prior reports in rheumatoid arthritis [22] and gout [23], comfort and fit were highlighted by patients with SLE as being the most important footwear factors. Interestingly, people with SLE also rated their footwear as being less suitable and less comfortable compared to control participants. This may reflect the difficulty that people with SLE have in wearing different shoes [11]. A recent survey found that $27 \%$ of people with SLE reported that they would like to receive footwear advice, while $23 \%$ reported having received advice related to footwear [10]. Finding appropriate footwear has been identified as a major barrier to footwear-based treatment in people with inflammatory arthritis $[18,25,26]$. 
Table 2 Footwear characteristics ${ }^{a}$

\begin{tabular}{|c|c|c|c|}
\hline & SLE & Control & $P$ \\
\hline Appropriate fit in length & $14(66 \%)$ & $14(70 \%)$ & 0.33 \\
\hline Appropriate fit in width & $17(77 \%)$ & $18(90 \%)$ & 0.27 \\
\hline Age of shoe $>12$ months & $12(55 \%)$ & $8(40 \%)$ & 0.35 \\
\hline Partly or fully worn tread & $20(91 \%)$ & $13(65 \%)$ & 0.041 \\
\hline Footwear style & & & 0.34 \\
\hline Walking shoe & $7(32 \%)$ & $7(35 \%)$ & \\
\hline Athletic shoe & $0(0 \%)$ & $3(15 \%)$ & \\
\hline Boot & $1(5 \%)$ & $1(5 \%)$ & \\
\hline Sandal & $6(27 \%)$ & $5(25 \%)$ & \\
\hline High-heel & $1(5 \%)$ & $0(0 \%)$ & \\
\hline Court & $1(5 \%)$ & $0(0 \%)$ & \\
\hline Moccasin & $0(0 \%)$ & $2(10 \%)$ & \\
\hline Flip flops & $3(14 \%)$ & $1(5 \%)$ & \\
\hline Other & $3(14 \%)$ & $1(5 \%)$ & \\
\hline Classification of footwear & & & 0.47 \\
\hline Good & $7(32 \%)$ & $10(50 \%)$ & \\
\hline Average & $1(5 \%)$ & $1(5 \%)$ & \\
\hline Poor & $14(64 \%)$ & $9(45 \%)$ & \\
\hline Longitudinal profile & & & 0.37 \\
\hline Flat & $13(59 \%)$ & $12(60 \%)$ & \\
\hline Small heel rise & $7(32 \%)$ & $8(40 \%)$ & \\
\hline Large heel rise & $2(9 \%)$ & $0(0 \%)$ & \\
\hline Forefoot flexion point & & & 0.58 \\
\hline Level with MTPJs & $15(68 \%)$ & $12(60 \%)$ & \\
\hline Proximal/distal to MTPJs & $7(32 \%)$ & $8(40 \%)$ & \\
\hline Motion control properties scale (0-9), median (IQR) & $1.0(4.0)$ & $5.0(4.0)$ & 0.003 \\
\hline Presence of cushioning & & & 0.75 \\
\hline None & $8(36 \%)$ & $6(30 \%)$ & \\
\hline Heel & $2(9 \%)$ & $1(5 \%)$ & \\
\hline Heel and forefoot & $12(55 \%)$ & $13(65 \%)$ & \\
\hline Footwear comfort VAS, mm, median (IQR) & $78.0(34.0)$ & $90(29.0)$ & 0.024 \\
\hline Self-perceived footwear suitability VAS, mm, median (IQR) & $76.0(28.0)$ & $88.0(33.0)$ & 0.030 \\
\hline Foot pain VAS, mm, median (IQR) & $17.0(62.5)$ & $0.0(10.5)$ & 0.038 \\
\hline
\end{tabular}

${ }^{a}$ Values are presented as $\mathrm{n}(\%)$ unless otherwise specified. Bolded-p values indicate significant between group differences at $P<0.05$. MTPJs: metatarsophalangeal joints; VAS: visual analogue scale

The results from this study should be considered in light of a number of limitations. Firstly, the study involved a small number of participants which reduced the power of the study. Secondly, this study was conducted over summer in New Zealand and the results may vary in other countries and climates due to seasonal variation in footwear. The small sample size meant the study was underpowered to assess associations between footwear and foot problems in participants with SLE. Future studies may determine the relationship between characteristics of footwear worn by people with SLE and their foot pain, foot function and foot deformity. Future work may also assess the efficacy of footwear education on footwear habits, management of foot problems and reduction of foot pain in people with SLE.

\section{Conclusions}

In summary, this study has shown that compared to age- and sex-matched healthy volunteer controls, people with SLE wear shoes that are more worn and lack motion control properties. People with SLE also reported greater foot pain, and perceived their footwear to be less 
Table 3. Difference in footwear features considered important to people with SLE and controls

\begin{tabular}{llll}
\hline & SLE & Control & $P$ \\
\hline Comfort & $21(95 \%)$ & $20(100 \%)$ & 0.34 \\
Fit & $21(95 \%)$ & $20(100 \%)$ & 0.34 \\
Style & $19(86 \%)$ & $18(90 \%)$ & 0.72 \\
Ease to put on/off & $18(82 \%)$ & $10(50 \%)$ & $\mathbf{0 . 0 2 9}$ \\
Heel height & $17(77 \%)$ & $15(75 \%)$ & 0.86 \\
Support & $16(73 \%)$ & $15(75 \%)$ & 0.87 \\
Non-slip & $16(73 \%)$ & $11(55 \%)$ & 0.23 \\
Colour & $15(68 \%)$ & $13(65 \%)$ & 0.83 \\
Material & $14(64 \%)$ & $15(75 \%)$ & 0.43 \\
Cost & $12(55 \%)$ & $10(50 \%)$ & 0.77 \\
Weight & $10(45 \%)$ & $10(50 \%)$ & 0.77 \\
Fastening & $9(41 \%)$ & $7(35 \%)$ & 0.69 \\
\hline
\end{tabular}

Data are presented as $n(\%)$. Bolded-p values indicate significant between

group differences at $P<0.05$.

comfortable and less suitable. These findings may highlight the need for further consideration of the role of appropriate footwear and footwear advice in managing foot problems in people with SLE.

\section{Abbreviations}

SLE: Systemic lupus erythematosus; VAS: Visual analogue scale

\section{Acknowledgements}

We would like to thank M. Lobo and Dr R. Suppiah (Auckland District Health Board), Dr S. Kumar (Counties Manukau District Health Board), and Dr M. Corkill and Dr K. Ng (Waitemata District Health Board) for their assistance in the recruitment of participants.

\section{Ethical approval and consent to participate}

This study was approved by the Auckland University of Technology Ethics Committee (16/209). All participants provided written informed consent.

\section{Funding}

This study was funded by Arthritis New Zealand.

\section{Availability of data and materials}

The datasets used and analysed during the current study are available from the corresponding author on reasonable request.

\section{Author's contributions}

SS made substantial contributions to conception and design of the study, supervised data collection, contributed to analysis and interpretation of data and to writing the manuscript. MK undertook all data collection, and contributed to writing the manuscript. ABR contributed to study design and conception, interpretation of the data and writing of the manuscript. ND made substantial contributions to conception and design, to interpretation of data and to writing the manuscript. AA made substantial contributions to conception and design, to interpretation of data and to writing the manuscript. KR made substantial contributions to conception and design, to interpretation of data and to writing the manuscript. All authors were involved in drafting of the manuscript or revising it critically for important intellectual content. All authors read and approved the final manuscript.

\section{Consent for publication}

Not applicable

\section{Competing interests}

AUT receives funding from ASICS New Zealand to support general podiatric research. The authors declare no other competing interests.

\section{Publisher's Note}

Springer Nature remains neutral with regard to jurisdictional claims in published maps and institutional affiliations.

\section{Author details}

${ }^{1}$ Department of Podiatry, Health \& Rehabilitation Research Institute, Auckland University of Technology, Private Bag 92006, Auckland 1142, New Zealand.

${ }^{2}$ Faculty of Medical and Health Sciences, The University of Auckland, Private Bag 92019, Auckland 1142, New Zealand. ${ }^{3}$ Department of Rheumatology, Auckland District Health Board, P.O. Box 92189, Auckland, New Zealand.

Received: 25 April 2018 Accepted: 20 June 2018

Published online: 05 July 2018

\section{References}

1. Skaggs BJ, Hahn BH, McMahon M. Accelerated atherosclerosis in patients with SLE-mechanisms and management. Nat Rev Rheumatol. 2012;8:214-23.

2. Omdal R, Henriksen OA, Mellgren SI, Husby G. Peripheral neuropathy in systemic lupus erythematosus. Neurology. 1991;41:808-11.

3. Pipili C, Sfritzeri A, Cholongitas E. Deforming arthropathy in systemic lupus erythematosus. Eur J Intern Med. 2008;19:482-7.

4. lagnocco A, Ceccarelli F, Rizzo C, Truglia S, Massaro L, Spinelli FR, Vavala C, Valesini G, Conti F. Ultrasound evaluation of hand, wrist and foot joint synovitis in systemic lupus erythematosus. Rheumatology (Oxford). 2014;53:465-72.

5. Hassan AA, Habib HM, Eissa AA. Peripheral arterial disease in patients with systemic lupus erythematosus: a prospective controlled study. Int J Rheum Dis. 2013;16:319-24

6. Muro Y, Sugiura K, Morita Y, Tomita Y. An evaluation of the efficacy of the toe brachial index measuring vascular involvement in systemic sclerosis and other connective tissue diseases. Clin Exp Rheumatol. 2009;27:26-31.

7. Oomatia A, Fang H, Petri M, Birnbaum J. Peripheral neuropathies in systematic lupus erythematosus. Arthritis Rheumatol. 2014;66:1000-9.

8. Morales-Lozano R, Martinez-Barrio J, Gonzalez-Fernandez ML, Lopez-Longo FJ, Ovalles-Bonilla JG, Valor L, Janta I, Nieto JC, Hernandez-Florez D, Gonzalez CM, et al. The feet in systemic lupus erythematosus; are we underestimating their involvement and functional impact? Clin Exp Rheumatol. 2016;34:609-17.

9. Mizutani W, Quismorio FP Jr. Lupus foot: deforming arthropathy of the feet in systemic lupus erythematosus. J Rheumatol. 1984;11:80-2.

10. Cherry L, Alcacer-Pitarch B, Hopkinson N, Teh LS, Vital EM, Edwards CJ, Blake A, Williams AE. The prevalence of self-reported lower limb and foot health problems experienced by participants with systemic lupus erythematosus: Results of a UK national survey. Lupus. 2016;26:410-6.

11. Otter SJ, Kumar S, Gow P, Dalbeth N, Corkill M, Rohan M, Davies KA, Pankathelam S, Rome K. Patterns of foot complaints in systemic lupus erythematosus: a cross sectional survey. J Foot Ankle Res. 2016;9:10-7.

12. Tlacuilo-Parra A, Guevara-Gutierrez E, Mayorga J, Garcia-De La Torre I, Salazar-Paramo M. Onychomycosis in systemic lupus erythematosus: a case control study. J Rheumatol. 2003;30:1491-4.

13. Mukherjee S, Cherry L, Zarroug J, Culliford D, Bowen C, Arden N, Edwards C. A pilot investigation of the prevalence of US-detectable forefoot joint pathology and reported foot-related disability in participants with systemic lupus erythematosus. J Foot Ankle Res. 2016;9:27-32.

14. Barton CJ, Bonanno D, Menz HB. Development and evaluation of a tool for the assessment of footwear characteristics. J Foot Ankle Res. 2009;2:10-21.

15. Rome K, Stewart S, Vandal AC, Gow P, McNair PJ, Dalbeth N. The effects of commercially available footwear on foot pain and disability in people with gout: a pilot study. BMC Musculoskelet Disord. 2013;14:278-86.

16. Williams $A E$, Rome $K$, Nester CJ. A clinical trial of specialist footwear for patients with rheumatoid arthritis. Rheumatology (Oxford). 2007:46:302-7.

17. Naidoo S, Anderson S, Mills J, Parsons S, Breeden S, Bevan E, Edwards C, Otter S. "I could cry, the amount of shoes I can't get into": A qualitative exploration of the factors that influence retail footwear selection in women with rheumatoid arthritis. J Foot Ankle Res. 2011;4:21. 
18. Williams $A E$, Nester $C J$, Ravey MI. Rheumatoid arthritis patients' experiences of wearing therapeutic footwear - A qualitative investigation. BMC Musculoskelet Disord. 2007;8:104-11.

19. Petri M, Orbai AM, Alarcon GS, Gordon C, Merrill JT, Fortin PR, Bruce IN, Isenberg D, Wallace DJ, Nived O, et al. Derivation and validation of the Systemic Lupus International Collaborating Clinics classification criteria for systemic lupus erythematosus. Arthritis Rheum. 2012;64:2677-86.

20. Dufour AB, Broe KE, Nguyen US, Gagnon DR, Hillstrom HJ, Walker AH, Kivell E, Hannan MT. Foot pain: is current or past shoewear a factor? The Framingham Foot Study. Arthritis Rheum. 2009;61:1352-8.

21. Williams AE, Nester CJ. Patient perceptions of stock footwear design features. Prosthet Orthot Int. 2006;30:61-71.

22. Silvester RN, Williams AE, Dalbeth N, Rome K. Choosing shoes': a preliminary study into the challenges facing clinicians in assessing footwear for rheumatoid patients. J Foot Ankle Res. 2010:3:24-31.

23. Rome K, Frecklington M, McNair P, Gow P, Dalbeth N. Footwear characteristics and factors influencing footwear choice in patients with gout. Arthritis Care Res. 2011;63:1599-604.

24. Brenton-Rule A, Hendry GJ, Barr G, Rome K. An evaluation of seasonal variations in footwear worn by adults with inflammatory arthritis: a cross-sectional observational study using a web-based survey. J Foot Ankle Res. 2014;7:36-42.

25. Otter SJ, Lucas K, Springett K, Moore A, Davies K, Cheek L, Young A, WalkerBone $K$. Foot pain in rheumatoid arthritis prevalence, risk factors and management: an epidemiological study. Clin Rheumatol. 2010;29:255-71.

26. Hendry GJ, Gibson KA, Pile K, Taylor L, Du Toit V, Burns J, Rome K. "They just scraped off the calluses": a mixed methods exploration of foot care access and provision for people with rheumatoid arthritis in south-western Sydney, Australia. J Foot Ankle Res. 2013;6:34-45.

Ready to submit your research? Choose BMC and benefit from:

- fast, convenient online submission

- thorough peer review by experienced researchers in your field

- rapid publication on acceptance

- support for research data, including large and complex data types

- gold Open Access which fosters wider collaboration and increased citations

- maximum visibility for your research: over $100 \mathrm{M}$ website views per year

At BMC, research is always in progress.

Learn more biomedcentral.com/submissions 